\title{
Gastroesophageal reflux
}

\section{PRACTICAL ISSUES IN MEDICAL MANAGEMENT OF GASTROESOPHAGEAL REFLUX}

In patients with erosive or ulcerative esophagitis, the relapse rate of esophagitis and symptoms after successful antisecretory therapy varies between 42 and $80 \%$ within the first six months of cessation of this therapy.

Widespread clinical experience and indications from clinical trials suggest that for successful prevention of relapse, it is necessary to continue antisecretory drugs at the same dose as that required for healing.

In a 12 month follow-up study, it was shown that with omeprazole $20 \mathrm{mg}$ daily there were few relapses compared to omeprazole $20 \mathrm{mg}$ on the weekend (three days) or ranitidine $150 \mathrm{mg}$ bid.

One must consider current knowledge of the safety of long term treatment, its risks and benefits. There must be individualization of choice and intensity of treatment.

Other options for long term maintenance therapy such as prokinetic drugs are under investigation.

\section{A DOUBLE-BLIND STUDY DESIGNED TO COMPARE THE EFFECTS OF CISAPRIDE AND RANITIDINE ON ENDOSCOPIC HEALING RATES IN REFLUX ESOPHAGITIS}

The effects of cisapride $20 \mathrm{mg}$ bid, cisapride $10 \mathrm{mg}$ qid and ranitidine $150 \mathrm{mg}$ bid over eight and 12 weeks were evaluated. Each treatment resulted in a statistically significant decrease of the esophagitis severity grade.

There was no statistically significant intergroup difference.

\section{CISAPRIDE REDUCES THE RELAPSE RATE IN REFLUX ESOPHAGITIS}

The authors reported a multinational study aimed at evaluating maintenance treatment with cisapride over 12 months.

After healing with antisecretory drugs, 443 patients were randomized to double-blind treatment with cisapride $10 \mathrm{mg}$ bid or $20 \mathrm{mg}$ at night, or placebo.

At endpoint relapse rates were, respectively, 27.5, 28.4 and $48.5 \%$. The authors concluded that cisapride is efficacious in preventing relapse of esophagitis and that bedtime administration is equivalent to twice daily intake.

\section{PROKINETICS FOR ESOPHAGEAL DISEASE}

If one considers that gastroesophageal reflux disease results from a basal decrease in lower esophageal sphincter pressure, abnormal esophageal clearing and delayed gastric emptying, it may well be related to a primary motor disorder. Cisapride $40 \mathrm{mg}$ daily is as effective as ranitidine $150 \mathrm{mg}$ bid in healing grade Il esophagitis after a 12 week period.

Since gastroesophageal reflux is a chronic disease, the aim must be the prevention of relapse.

Relapse seems to be inversely related to the strength of acid suppression during treatment. Relapse rates of $80 \%$ have been observed after omeprazole therapy. High maintenance doses may be required. Safety must be established. Maintenance doses of $\mathrm{H}_{2}$ blockers have not been shown to be efficacious in preventing relapse.

The relapse rate after one year of cisapride $20 \mathrm{mg}$ daily was approximately $24 \%$ compared to $48 \%$ with placebo. Cisapride is the first 'prokinetic' drug that has proven efficacious for both healing and preventing relapse of esophagitis. 


\section{A PROSPECTIVE STUDY ON THE PREVALENCE OF ESOPHAGEAL CHEST PAIN IN 248 PATIENTS REFERRED TO CARDIOLOGISTS FOR SUSPECTED MYOCARDIAL ISCHEMIA}

Patients underwent coronary angiograms. Previously documented heart disease patients were excluded. Full esophageal testing was performed. Acid perfusion and edrophonium stimulation were considered the most valuable screening tests. The authors suggested restriction of $24 \mathrm{~h} \mathrm{pH}$ monitoring and pressure recording to patients with a positive response to the above tests.

Results have shown that in $51 \%$ of patients with normal coronary angiography, pain is of esophageal origin.

\section{ESOPHAGEAL MOTILITY DISORDERS AFTER CHRONIC ALCOHOL EXPOSURE}

Chronic alcohol intake increased the mean amplitude of peristaltic waves in the middle and distal esophagus. In ap- proximately $50 \%$ of cases, there was a mostly asymptomatic nutcracker esophagus.

In pathological gastroesophageal reflux, lower esophageal sphincter pressure and mean amplitude of peristaltic waves are decreased in comparison to chronic alcoholism without reflux.

In comparison to controls, the peristaltic waves and relaxation time of the lower esophageal sphincter in chronic alcoholism is increased. This could explain why gastroesophageal reflux is increased in alcoholism.

Autonomic neuropathy does not change the pattern of motility in chronic alcoholism.

The underlying mechanism(s) of motor disorder in alcoholism remains unknown.

S Lemire, MD, FACG Department of Gastroenterology, Hôpital de l'Enfant-Jésus Quebec City, Quehec 


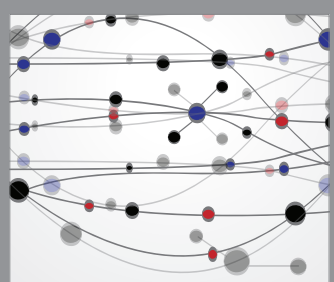

The Scientific World Journal
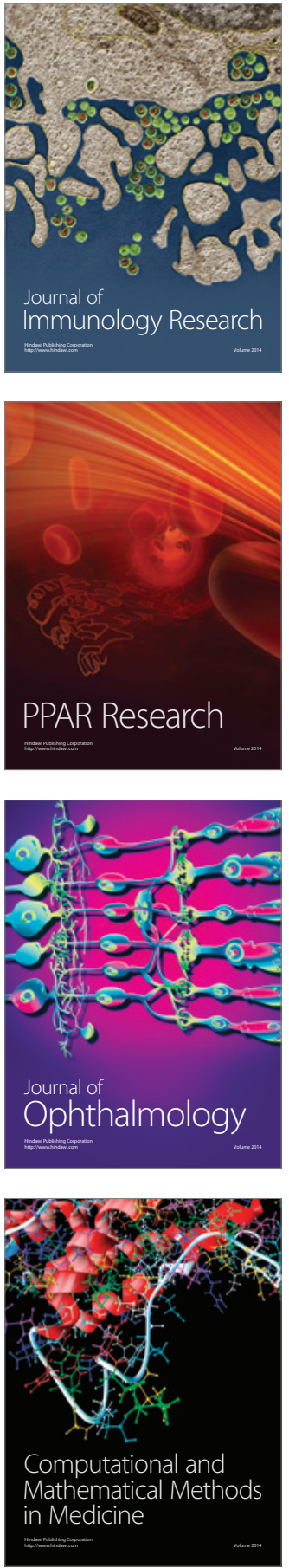

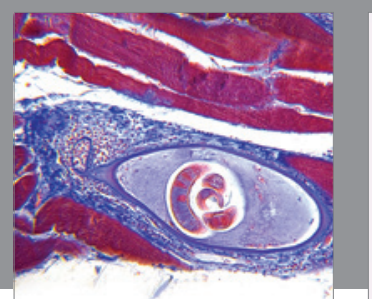

Gastroenterology Research and Practice

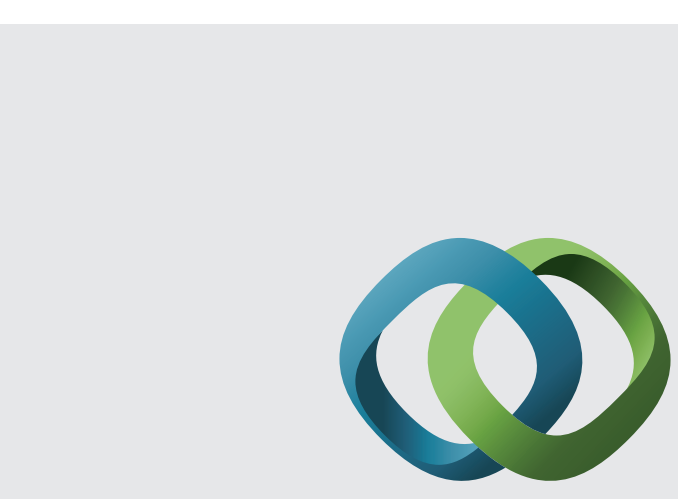

\section{Hindawi}

Submit your manuscripts at

http://www.hindawi.com
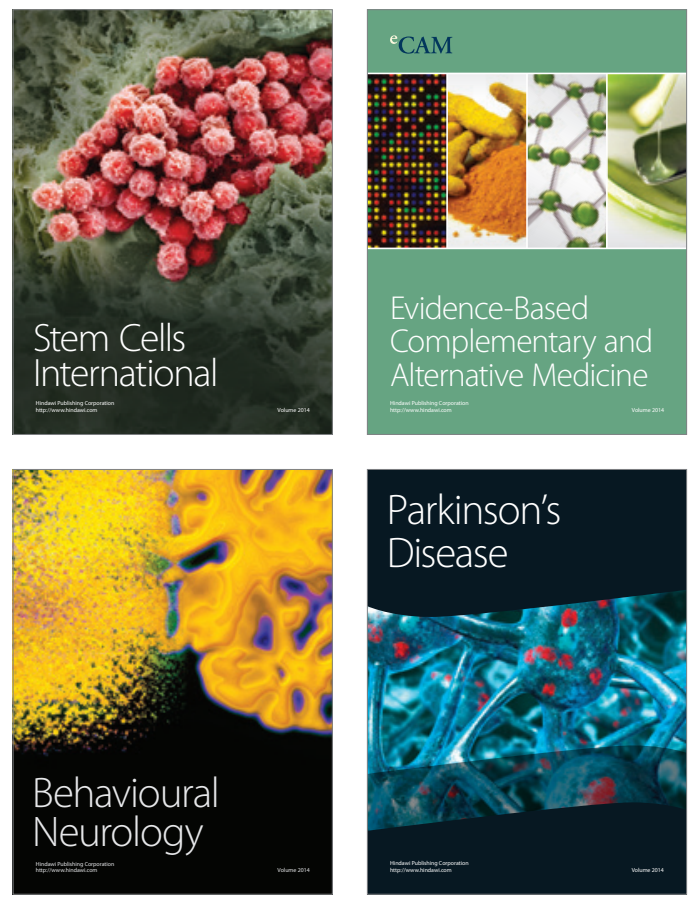
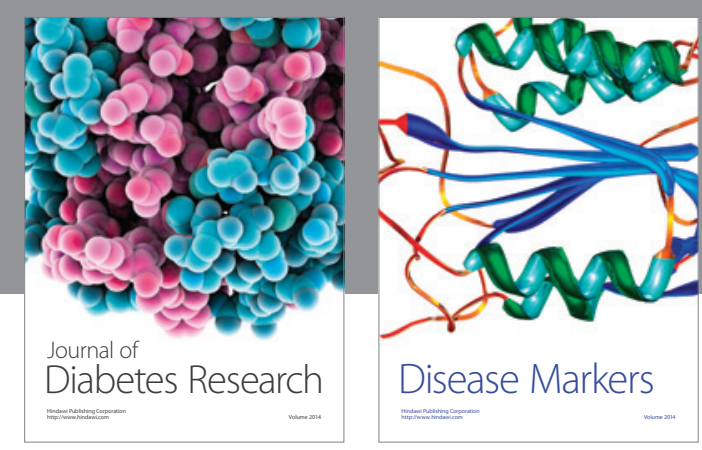

Disease Markers
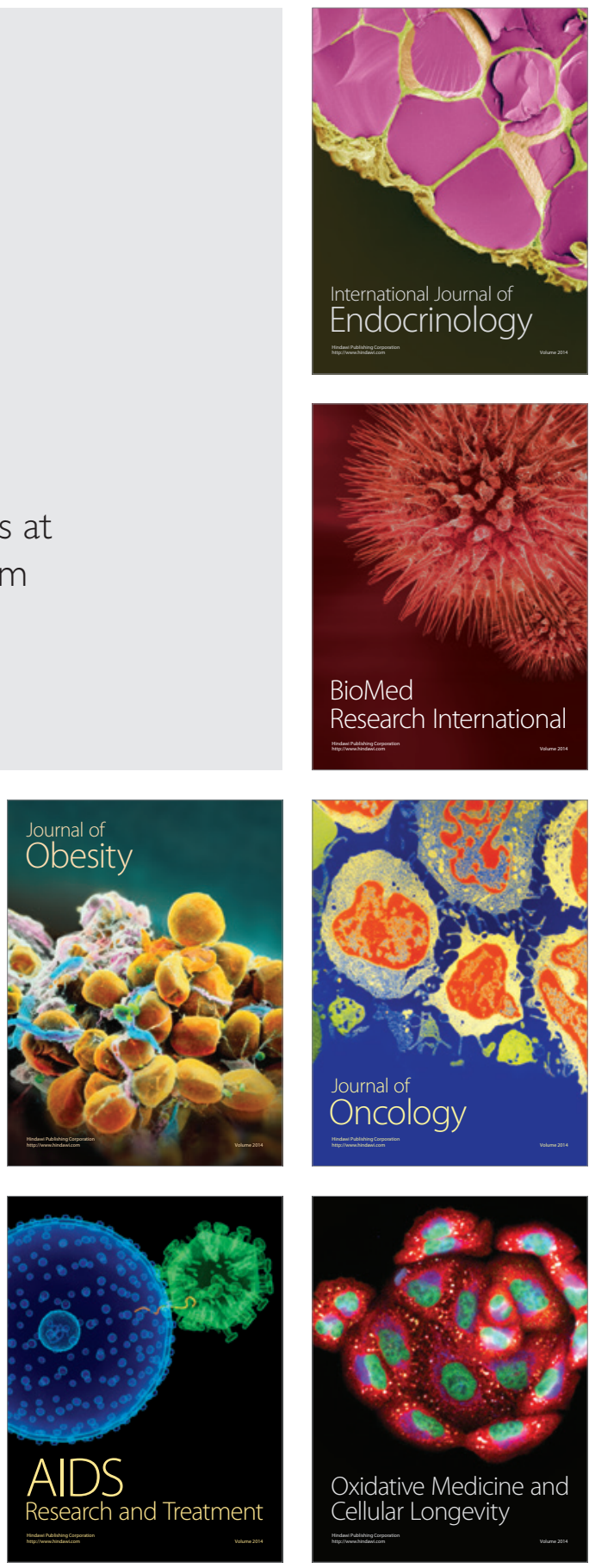